\title{
An Assessment of the Morbidity and Mortality in Eclampsia: A Study in a Tertiary Care Hospital
}

\author{
Dr. Jannatul Ferdous ${ }^{1 *}$, Dr. Goury Prava Dhar ${ }^{2}$, Dr. Mahbubur Rahman ${ }^{3}$, Dr. Mohammad Mostafizur Rahman ${ }^{4}$
}

\author{
${ }^{1}$ Associate Professor, Department of Gynae \& Obstetric, Ashiyan Medical College Hospital, Barua Khilkhet, Dhaka, Bangladesh \\ ${ }^{2}$ Faculty, Evolution Health Academy, Miami Garden, Florida-33169, USA \\ ${ }^{3}$ Associate Professor, Department of Gynae \& Obstetric, OSD, DGHS, Mohakhali, Dhaka Attached with Patuakhali, Medical College, Patuakhali, \\ Bangladesh \\ ${ }^{4}$ Assistant Professor \& Head, Dept. of Anesthesiology \& ICU, Ashiyan Medical College Hospital, Barua Khilkhet, Dhaka, Bangladesh
}

DOI: $10.36347 /$ sjams.2020.v08i09.024

| Received: 07.09.2020 | Accepted: 17.09.2020 | Published: 19.09.2020

*Corresponding author: Dr. Jannatul Ferdous

\section{Abstract}

Original Research Article

Introduction: A perinatal condition in eclampsia is a major concern of infant injury and death in developing countries like Bangladesh. Eclampsia is the commonest cause of convulsions in pregnancy next being epilepsy. So proper initiatives against eclampsia can save many lives by decreasing the total mortality as well as the morbidity of child and mother. Aim of the study: The aim of our study was to assess the perinatal mortality and morbidity which are related to eclampsia. Methods: This was a cross sectional observational study carried out in the Department of Obstetrics and Gynaecology in 250 Bedded General Hospital, Ashiyan Medical College Hospital, Barua Khilkhet, Dhaka, Bangladesh during the period from June 2016 and July 2017. Proper written consent form all the participants were obtained and the ethical committee of the hospital had approved the study before starting the intervention. In total 178 pregnant women with eclampsia were finalized as the study population. Result: In our study we found in total 148 live births from total 178 mothers which were $83.15 \%$ against total study population. Among all the babies 139 were survived which was $93.91 \%$ among total live births. Death after birth was 9 in number which was $6.08 \%$ among total live births. Early neonatal death was 13 in number which was $7.3 \%$ against total mothers. Stillbirths were 16 in number which was $9 \%$ against total mothers. In perinatal complication analysis we found 42 babies with jaundice which was $28.38 \%$ among live births. Babies with septicemia were 28 (18.92\%), with respiratory distress 25 (16.89\%), with neonatal convulsion were 7 (4.73\%) and with no complication were 46 (31.08\%). Conclusion: In the conclusion, we can say that stillbirth is the main component of perinatal death and prematurity is an important cause of perinatal loss in eclampsia. So, early referral of eclampsia patients, early resuscitative measures and good neonatal care can improve perinatal outcome.

Keywords: Eclampsia, Pregnancy, Primipara, Stillbirth.

Copyright @ 2020: This is an open-access article distributed under the terms of the Creative Commons Attribution license which permits unrestricted use, distribution, and reproduction in any medium for non-commercial use (NonCommercial, or CC-BY-NC) provided the original author and source are credited.

\section{INTRODUCTION}

Eclampsia (Greek "Shining forth") is an acute and life threatening complication of pregnancy, Characterized by convulsions and unexplained coma in a patient with signs and symptoms of pre eclampsia during pregnancy or postpartum period [1]. It has remained as a major public health threat both in developed and developing countries, Contributing to maternal and perinatal morbidity and mortality. Preeclampsia precursor to eclampsia ranges between 2 $\%$ to $10 \%$ of total pregnancies worldwide. WHO estimates incidence of preeclampsia is seven times higher in developing countries than developed world [2]. The incidence of eclampsia in developed countries is estimated to about $5-7 / 10,000$ deliveries. Whereas in developing nations varies widely 1 case per 100 to 1 case per 1700 pregnancies [3] Eclampsia defined as 'the occurrence of convulsion associated with pregnancy complicated by preeclampsia [4]'. Existing research and data reports that globally ten million women develops pre-eclampsia each year; of which 76,000 women die from this condition. Most of these deaths occur in Low and Middle Income Countries (LMICs) [5]. Furthermore, women in developing countries are likely to develop eclampsia ten times higher than these in the developed countries [6]. In Bangladesh as it is elsewhere in the developing countries eclampsia is a major cause of maternal\& perinatal injury and death. Despite the incidence dropped to $0.2 \%-0.5 \% 4$ of all deliveries, the incidence remains $5 \%$ of in Bangladesh [7]. It is said that, eclampsia appears as one of the five 
major causes of maternal mortality. Additionally, eclampsia is responsible for stillbirth and neonatal injury and death in the country. Eclampsiaoften result in low-birth weight (LBW), Intrauterine Growth Retardation (IUGR), neonatal asphyxia, and neonatal hyperbilirubinemia, and neonatal sepsis, prematurity and neonatal asphyxia [8]. In 2017, a survey shows $29 \%$ perinatal death was observed among the eclampsia patients in a hospital [9]. Another hospital study shows that $32.8 \%$ perinatal death rate occurred among the patient with eclamptic condition. However, due to limited number of facilities-based service provision, availability, and affordability of patients a limited and/or no studies were conducted investigating fetal and maternal outcome of eclampsia in Bangladesh. Considering the scant amount of evidence we carried out this study in an attempt to assess perinatal outcome relating to clinical types and management of eclampsia. We believe this study will provide give new information that will help to policy planers, to formulate strategies to improve perinatal outcome in eclampsia and will create some interest for further research. There had been very limited study in Bangladesh regarding the morbidity and mortality in eclampsia. So we hope the findings of this study may be helpful for further studies.

\section{OBJeCTIVES}

a) General objective

- To assess the perinatal morbidly and mortality which are related to eclampsia in Bangladesh

\section{b) Specific Objectives}

- To assess the prevalence of perinatal death related to eclampsia in Bangladesh

- To assess the risk factors of eclampsia in women in Bangladesh

\section{Methodology \& Materials}

This was a cross sectional observational study carried out in the Department of Obstetrics and Gynaecology in Ashiyan Medical College Hospital, Barua Khilkhet, Dhaka, Bangladesh during the period from June 2016 and July 2017. Proper written consent form all the participants were obtained and the ethical committee of the hospital had approved the study before starting the intervention. In total 178 pregnant women with eclampsia were finalized as the study population.

Eclampsia patients admitted to this hospital during the study period constitute the samples. After admission, diagnosis was made mostly on the basis of history and clinical presentation with minimum aids. We used Face to face interview, examination finding \& investigation report, Semi structured questionnaire \& check list. Through proper administrative procedure by the researcher took the verbal consent of the patient to interview and examine her. Finding was recorded after data collection, data were checked for consistency and necessary corrections were made of needed. Data were collected and analyzed by using MS-Excel and SPSS version 20. According to the exclusion criteria, patients who were discharged within 48 hours of delivery and cases other than clinically confirmed eclampsia were excluded from the study.

\section{RESULT}

In our study among all the participants we found most of the cases were from 20 to 30 years age group. The number was 120 which were $67.42 \%$ of total population. This trend was followed by $37(20.79 \%)$ from $>30$ years age group and $21(11.80 \%)$ from $<20$ years age group. In socio-economic status analysis we found the highest cases from lower class people which $47.75 \%(n=85)$. This trend was followed by 59 (33.15) from middle class and $34(19.10 \%)$ from higher class families. Most of the cases of our study were with 1-2 parity and their number was $95(53.37 \%)$. It was followed by $69(38.76 \%)$ with no parity and $14(7.87 \%)$ with three or more parity. In our study we found most of the patients taken irregular antenatal care. The number of such type of cases was 98 (55.06\%). This trend was followed by $49(27.53 \%)$ had not taken antenatal care at all and only $31(17.42 \%)$ patients taken proper antenatal care. As per the report of gestation period we found $95(53.37 \%)$ were with gestation of 2936 weeks which was the highest. This trend was followed by $71(39.89 \%)$ were with $>37$ weeks and 12 $(6.74 \%)$ were with $<28$ weeks. In our study we found in total 148 live births from total 178 mothers which were $83.15 \%$ against total study population. Among all the babies 139 were survived which was $93.91 \%$ among total live births. Death after birth was 9 in number which was $6.08 \%$ among total live births. Early neonatal death was 13 in number which was $7.3 \%$ against total mothers. Stillbirths were 16 in number which was $9 \%$ against total mothers. In perinatal complication analysis we found 42 babies with jaundice which was $28.38 \%$ among live births. Babies with septicemia were $28(18.92 \%)$, with respiratory distress $25(16.89 \%)$, with neonatal convulsion were $7(4.73 \%)$ and with no complication were $46(31.08 \%)$.

Table-I: Age distribution of participants $(\mathrm{N}=178)$

\begin{tabular}{|c|c|c|}
\hline Age (Years) & $\mathbf{n}$ & \% \\
\hline$<\mathbf{2 0}$ & 21 & 11.80 \\
\hline $\mathbf{2 0 - 3 0}$ & 120 & 67.42 \\
\hline$>\mathbf{3 0}$ & 37 & 20.79 \\
\hline
\end{tabular}


Table-II: Distribution of socio-economic status of participants $(\mathrm{N}=178)$

\begin{tabular}{|c|c|c|}
\hline Status & n & \% \\
\hline Lower & 85 & 47.75 \\
\hline Meddle & 59 & 33.15 \\
\hline Higher & 34 & 19.10 \\
\hline
\end{tabular}

Table-III: Distribution of parity of participants $(\mathrm{N}=178)$

\begin{tabular}{|c|c|c|}
\hline Parity & n & \% \\
\hline $\mathbf{0}$ & 69 & 38.76 \\
\hline $\mathbf{1 - 2}$ & 95 & 53.37 \\
\hline$\geq \mathbf{3}$ & 14 & 7.87 \\
\hline
\end{tabular}

Table-IV: Status of antenatal care of participants $(\mathrm{N}=178)$

\begin{tabular}{|c|c|c|}
\hline Antenatal care & $\mathbf{n}$ & $\mathbf{\%}$ \\
\hline None & 49 & 27.53 \\
\hline Irregular & 98 & 55.06 \\
\hline Regular & 31 & 17.42 \\
\hline
\end{tabular}

Table-V: Duration of gestation among participants $(\mathrm{N}=178)$

\begin{tabular}{|c|c|c|}
\hline Duration (Week) & n & \% \\
\hline$<28$ & 12 & 6.74 \\
\hline $\mathbf{2 9 - 3 6}$ & 95 & 53.37 \\
\hline$>37$ & 71 & 39.89 \\
\hline
\end{tabular}

Table-VI: Outcome of pregnancies among the study participants

\begin{tabular}{|l|c|c|}
\hline Parameters & n & \% \\
\hline Live birth & 148 & 83.15 \\
\hline Survived & 139 & 93.91 \\
\hline Death after birth & 9 & 6.08 \\
\hline Early neonatal death (END) & 13 & 7.30 \\
\hline Stillbirth ( SB) & 16 & 8.99 \\
\hline Macerated & 3 & 1.69 \\
\hline Perinatal death (END + SB) & 29 & 16.29 \\
\hline
\end{tabular}

Table-VII: Distribution of perinatal conditions/complication among live birth $(n=148)$

\begin{tabular}{|l|c|c|}
\hline Complications & $\mathbf{n}$ & \% \\
\hline Jaundice & 42 & 28.38 \\
\hline Septicemia & 28 & 18.92 \\
\hline $\begin{array}{l}\text { Respiratory } \\
\text { distress }\end{array}$ & 25 & 16.89 \\
\hline $\begin{array}{l}\text { Neonatal } \\
\text { convulsion }\end{array}$ & 7 & 4.73 \\
\hline No complication & 46 & 31.08 \\
\hline
\end{tabular}

\section{DISCUSSION}

Incidence of eclampsia in the hospitals of developing country is higher than the other part of the globe. The incidence of Eclampsia in Eastern India is $3.2 \%$. In Kerla is $3.8 \%, 4.9 \%$ in Andra Pradesh, $15 \%$ in Madya Pradesh and $20.7 \%$ in Bihar [10]. These figures are higher compare to developed countries. In a study they stated, 'the incidence of 1 in 3250 pregnancies in US [11] and 1 in 2000 pregnancy in Europe [12] were found. In developed countries, the incidence of eclampsia is significantly low probably because of the comprehensive antenatal care, early detection of pre eclampsia, and its management, and uniform national health care policy. Majority of our cases $(88 \%)$ were un-booked cases and/or irregular Antenatal care, and with low socio economic status. The signs and symptoms of pre eclampsia were not detected until development of eclampsia was observed. In our study eclampsia was common in young pregnant woman same as in the $(83 \%)$ study of Chaurvedi et al. [13]. The hypertensive disorders during pregnancy are important causes of maternal death throughout the world and most of these deaths are attributed to eclampsia. The hypertensive disorders also contribute extensively to still birth and neonatal morbidity and death. Hypertensive expectant mothers (or gravidas) are predisposed to the development of petentially lethal complications of pregnancy notably abruptio placentae, disseminated intravascular coagulation cerebral 
haemorrhage hepatic failure and acute renal failure. Perinatal death was very high in our study compared to Baha's [9] study $(11.8 \%)$. But in Bangladesh in several studies perinatal death were $32.1 \% 7,28 \% 8$ and $26.8 \%$ [14]. In a review of four different studies presented at the First International Conference of Obstetrics and Gynecology held in Bangladesh, perinatal mortality in eclampsia varied from (31 to 41)\%[16], and it appeared very high in comparison to general perinatal mortality rate in Bangladesh which at present is 70 per thousand livebirths[17]. In developed country, perinatal mortality in pre-eclampsia varied from 35 to $160 / 10005$. In our study $27.53 \%$ of them had no antenatal care (ANC); $55.06 \%$ had irregular ANC or were attending the hospital for the first time after being referred. Most of them came from low socioeconomic background. In our present study the majority of patients belong to age group of $20-30(67.42 \%)$ years. Several studies were done to see the risk factors of perinatal outcome of eclampsia and showed that eclampsia was found to be particularly common in adolescent and young pregnant women. The finding is consistent with the study done by chowdhury $\mathrm{P}$, as the adolescent pregnancy constitutes a large number of hospital admission in obstetric unit and it may explain the higher no of cases of eclampsia in this age group. Regarding parity, our study shows eclampsia was significantly associated in primigravida $(53.37 \%)$ and this finding is consistent with finding of Acharya G et al. (71.42\%) this may explain the immunological causes for preeclampsia and eclampsia and PND is the highest in this group. According to perinatal outcome, it shows that $83.15 \%$ was born alive and total still birth in eclamptic patients were $9 \%$ which are similar to study previously done in Bangladesh. In our study, perinatal death was $16.29 \%$ which is lower than that of study done by chowdhury $\mathrm{P}$ where the rate was $20 \%$ Patan hospital $31.25 \%, 38.6 \%$. In ours study also shows that $31.08 \%$ babies out of 148 live birth had no complication and $28.38 \%$ developed neonatal jaundice, $18.92 \%$ had developed septicemia, $16.89 \%$ had respiratory distress and $4.73 \%$ suffered from neonatal convulsion. This statistics is similar to many studies done in Bangladesh, previously. This cause of still birth may be due to late arrival of patients after onset of fits result in severe intrauterine hypoxia and intrauterine death. This may reflect lack of public awareness, lack of antenatal checkup neglected position of female in the family poor decision making ability of female, poor communication system and demerits of conservative approach in patient management. Causes of early neonatal death may be due to high rate of eclampsia in preterm pregnancy causing high preterm delivery and high perinatal loss. Other causes may be influenced by the availability and skills of neonatal care facilities in hospitals.

\section{Limitations of THE STUdy}

This was a single centered study with a small sized sample. So the findings of this study may not reflect the exact scenario of the whole country.

\section{CONCLUSION AND RECOMMENDATIONS}

Stillbirth is the main component of perinatal death and prematurity is an important cause of perinatal loss in eclampsia. So, early referral of eclampsia patients, early resuscitative measures and good neonatal care can improve perinatal outcome. We would like to recommend for conducting more study on the same issue with some larger sample size in several places to get more specific findings.

\section{REFERENCES}

1. Baha M Sibai, Diagnosis prevention and management of eclampia, American college of obstetrician and gynecologists.2005; 105(2): 402-410.

2. WHO. Make every mother and child count, in the worldhealth report 2005. Geneva, Switzerland: World HealthOrganization; 2005.

3. World Health Organization. Global Program to Conquer Preeclampsia/ Eclampsia. 2002.

4. Arias F, Bhide AG, Arulkumaran S, Damania K, Daftary SN. Practical Guide to High Risk Pregnancy and Delivery-E-Book. Elsevier health sciences; 2012.

5. World Health Organization. WHO recommendations for prevention and treatment of pre-eclampsia and eclampsia. 2011.

6. Preeclampsia Foundation. Preeclampsia and Maternal Mortality: a Global Burden. 2015.

7. Khatun S, Nilufar S, Bhuiyan AB, Begum K. Perinatal outcome in eclampsia. Bangladesh $\mathbf{J}$ Obstet Gynaecol 1994; 9:53-60.

8. Alam IP, Akhter S. Perinatal Outcome of Eclampsia in Dhaka Medical College Hospital.

9. Shamsuddin L, Rouf S, Khatoon H. Perinatal outcome in eclampsia. Bangladesh J Obstet Gynaecol. 1995; 10:65-72.

10. Sontakke P, Reshmi RS, Sebastian D. Obstetric morbidity among currently married women in selected states of India. J Fam Welf. 2009; 55: 17-26.

11. Ventura SJ, Martin JA, Curtin SC. Births: Final date for 1998. National Vital Statistics Reports, Hyattsville, Md, National Center for Health Statistics. 2000; 48(3).

12. Douglas KA, Redman CWG. Eclampsia in the United Kingdom. BMJ. 1994; 309:1395-1400.

13. Sarika Chaturvedi, Bharat Randive, and Nerges Mistry, Availability of Treatment for Eclampsia in Public Health Institutions in Maharashtra, India J Health Popul Nutr. 2013 March; 31(1): 86-95. 
14. Rao KB. Perinatal mortality. In: Ratnam SS, Rao $\mathrm{KB}$, Kumaran SA. Obsterics and gyanaecology for postgraduates. Vol. 2, 1st ed. Chennai: Orient Longman Ltd. 1997; 20: 252-9.

15. Robson SC. Hypertensiona and renal disease in pregnancy. In: Edmonds DK, editor. Dewhurst's text book of obstetrics and gynaecology for postgraduates. 6th ed. London: Blackwell Science Lt., 1999: 166-77.
16. Datta DC. Textbook of obstetric including perinatilogy and contraception. 4th ed. Calcutta. 1998; 51(51): 236-9, 648-9.

17. Robson SC. Hypertensiona and renal disease in pregnancy. In: Edmonds DK, editor. Dewhurst's text book of obstetrics and gynaecology for postgraduates. 6th ed. London: Blackwell Science Lt., 1999: 166-77. 